\title{
Research Paper: The Cross-cultural Adaptation of the Smartphone Addiction Scale to Persian
}

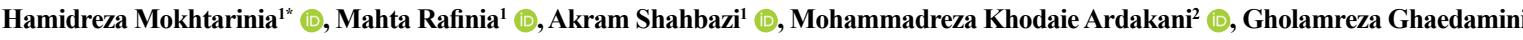 \\ Harouni $^{3}$ (D), Charls Philip Gabel ${ }^{4}$ (1)
}

1. Department of Ergonomics, University of Social Welfare and Rehabilitation Sciences, Tehran, Iran.

2. Psychosis Research Center. University of Social Welfare and Rehabilitation Sciences, Tehran, Iran.

3. Social Welfare Management Research Center, University of Social Welfare and Rehabilitation Sciences, Tehran, Iran.

4. Independent Researcher Coolum Beach, Sunshine Coast, QLD, Australia.

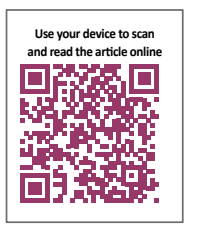

Citation: Mokhtarinia H, Rafinia M, Shahbazi A, Khodaie Ardakani M, Ghaedamini Harouni G, Philip Gabel C. The Crosscultural Adaptation of the Smartphone Addiction Scale to Persian. Iranian Rehabilitation Journal. 2020; 18(1):91-98. http:// dx.doi.org/10.32598/irj.18.1.919.1

http://dx.doi.org/10.32598/irj.18.1.919.1

Article info:

Received: 19 Jun 2019

Accepted: 05 Oct 2019

Available Online: 01 Mar 2020

Keywords:

Psychometrics, Validation, Smartphone, Addiction

\section{ABSTRACT}

Objectives: instruments and methods evaluate addiction to the Internet, mobile, and smartphone use. Subject-reported outcome measures, such as the Smartphone Addiction Scale (SAS) assess such addiction. The objectives of this study were to cross-culturally adapt the SAS into Persian (SAS-Pr) and to evaluate the properties of reliability and validity in the Persian setting.

Methods: The English version of the SAS was translated into Persian according to the published guidelines, using forward-translation, synthesis, back translation, consolidated consensus translations from an expert committee, and in pilot-testing. The pilot trial was performed with recruited medical students $(n=50)$ with an interview used to determine the comprehensibility, readability, understandability, interpretation, and cultural relevance of the questionnaire. A further sample of medical students $(n=100)$ was recruited for test-retest reliability performed at baseline and 7-14 days later, using the intraclass correlation coefficient $\left(\mathrm{ICC}_{2,1}\right)$ and internal consistency using Cronbach's $\alpha$.

Results: The translation of SAS-Pr was achieved with minimum difficulty. During this process, item 15 was revised and in items 24 and 25, the "telegram" phrase was added. The participants found the comprehensibility, readability, understandability, interpretation, and completeness of the questionnaire conclusive. Furthermore, high levels of test-retest reliability $\left(\mathrm{ICC}_{2,1}=0.81\right)$ and internal consistency $(\alpha=0.948)$ were obtained.

Discussion: The SAS-Pr adaptation was successful and the translated version showed promising positive psychometric properties. The SAS-Pr can be applied in research settings and in identifying Persian-speaking people at risk of addiction to the smartphone.

\section{* Corresponding Author:}

Hamid Reza Mokhtarinia, PhD.

Address: Department of Ergonomics, University of Social Welfare and Rehabilitation Sciences, Tehran, Iran.

Tel: +98 (21) 22180119

E-mail:hrmokhtarinia@yahoo.com 


\section{Highlights}

- Addiction to smartphone and the Internet is considered a major area of health concern.

- The identification of smartphone overuse, with possible addiction, and the identification of those at risk of becoming addicted appear necessary.

- The Smartphone Addiction Scale (SAS) is a self-reported developed scale, which assesses the pathological smartphone use and potential addiction.

- A Persian version was obtained, which was culturally and linguistically equivalent to the original version.

\section{Plain Language Summary}

The identification of smartphone overuse, with possible addiction, and the identification of those at risk of becoming addicted appear necessary. There are a variety of instruments designed to assess smartphone addiction. Among them, the SAS is the most valid and reliable one, which is translated into various languages. Because of the potential for cultural differences in health and usage habits, outcome tools should be systematically translated and adapted and, then, validated for use within different cultural contexts. The present research reported the successful psychometric evaluation of an applicable tool that measures pathological smartphone use and potential addiction.

\section{Introduction}

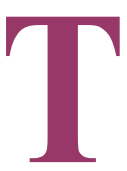

he use of smartphone has increased significantly during the last decade. Almost twothirds of the global population now own or use a mobile phone, over $50 \%$ of whom use a smartphone $[1,2]$. The results of a 40-nation survey showed that South Korea (88\%), Australia $(77 \%)$, and the United States $(72 \%)$ are the nation with the highest smartphone ownership rate, respectively [1]. The rate of smartphone users was $83.6 \%$ in Korea [3]. In China, the number of smartphone users is forecasted to grow to around 675 million in 2019 , up by $20 \%$ from 563 million in 2016. However, in the United States, it is expected to reach 247.5 million users [4]. There are similar patterns of increasing use in Iran, where the number of smartphone users increased from 2 million users in 2013 to around 27 million in 2015. Also, the number of Internet users has increased 5-fold and more than $64 \%$ of Iranians use the Internet in their home settings [5].

Smartphone dependency can be associated with symptoms, including infatuation, irregularity, mentally involved by the device, inappropriate use in a social or hazardous situation, feeling anger, anxiety, and permanent concern about the battery's charge life $[2,6]$. There are also other complications related to excessive smartphone use that include musculoskeletal complications in the neck, shoulders, and upper limbs. During such an increased frequency of smartphone use, the subsequent degree of neck flexion is increased and the body position is compromised; this leads to varying levels of symptom severity in terms of neck and shoulder pain [7].

Addiction to smartphone and the Internet is considered a major area of health concern, particularly concerning the negative effects on mental, physical, and psychosocial well-being. Smartphone addiction is related to the extent, to which individuals display pathological smartphone use causing harm to themselves and or others. The identification of smartphone overuse, with possible addiction, and the identification of those at risk of becoming addicted appear necessary. A variety of instruments assess smartphone addiction [8,9]; questionnaires are preferred because of their rapid and precise risk identification capacity. Various questionnaires exist for the Internet, mobile phone, and smartphone addiction, including the Internet addiction scale [10], problematic mobile phone use [11], and the Smartphone Addiction Scale (SAS) [8]. Among these, Persian versions of the Internet addiction scale [12] and problematic mobile phone use [13] can be found, but the SAS has not been adapted for the Persian language and culture. From the available literature, no scale evaluates smartphone addiction use in the Persian population.

The SAS was developed by Min Kwon (2013) as a self-reported scale, which assesses the pathological smartphone use and potential addiction [8]. Because of the potential for cultural differences in the health and 
smartphone usage, outcome measures should be systematically translated and adapted and, then, validated for use within different cultural contexts.

Consequently, the aims of this study included the translation and cultural adaptation of the SAS to Persian and the determination of the psychometric properties, including face validity and reliability of the pre-final SAS in a pilot population and the internal consistency.

\section{Methods}

\section{Smartphone Addiction Scale (SAS)}

In this research, the SAS was investigated and its cultural adaptation was evaluated. The SAS has 33 items in a 6-factor structure questionnaire that measures pathological smartphone use. Items are rated on a 6-point Lik- ert-scale, where a higher score indicates greater pathological smartphone use, and the total score ranges from 33 to 198 [8]. The incorporated factors include daily-life disturbance, positive anticipation, withdrawal, cyberspace-oriented relationship, overuse, and tolerance. The reliability and validity of the SAS in English [8], Turkish [2], and Malay [14] have been determined.

The cross-cultural adaptation of the SAS questionnaire was performed based on existing published guidelines [15] and previous research [16]. This has provided 6 steps as a template for cross-cultural adaptation and translation: 1) original translation; 2) synthesis; 3) back translation; 4) consensus by experts; 5) pilot-testing; and 6) the formulation of the definitive consensus translated version (Figure 1).

Two independent native Persian speakers translated the SAS into Persian (SAS-Pr). One translator was familiar

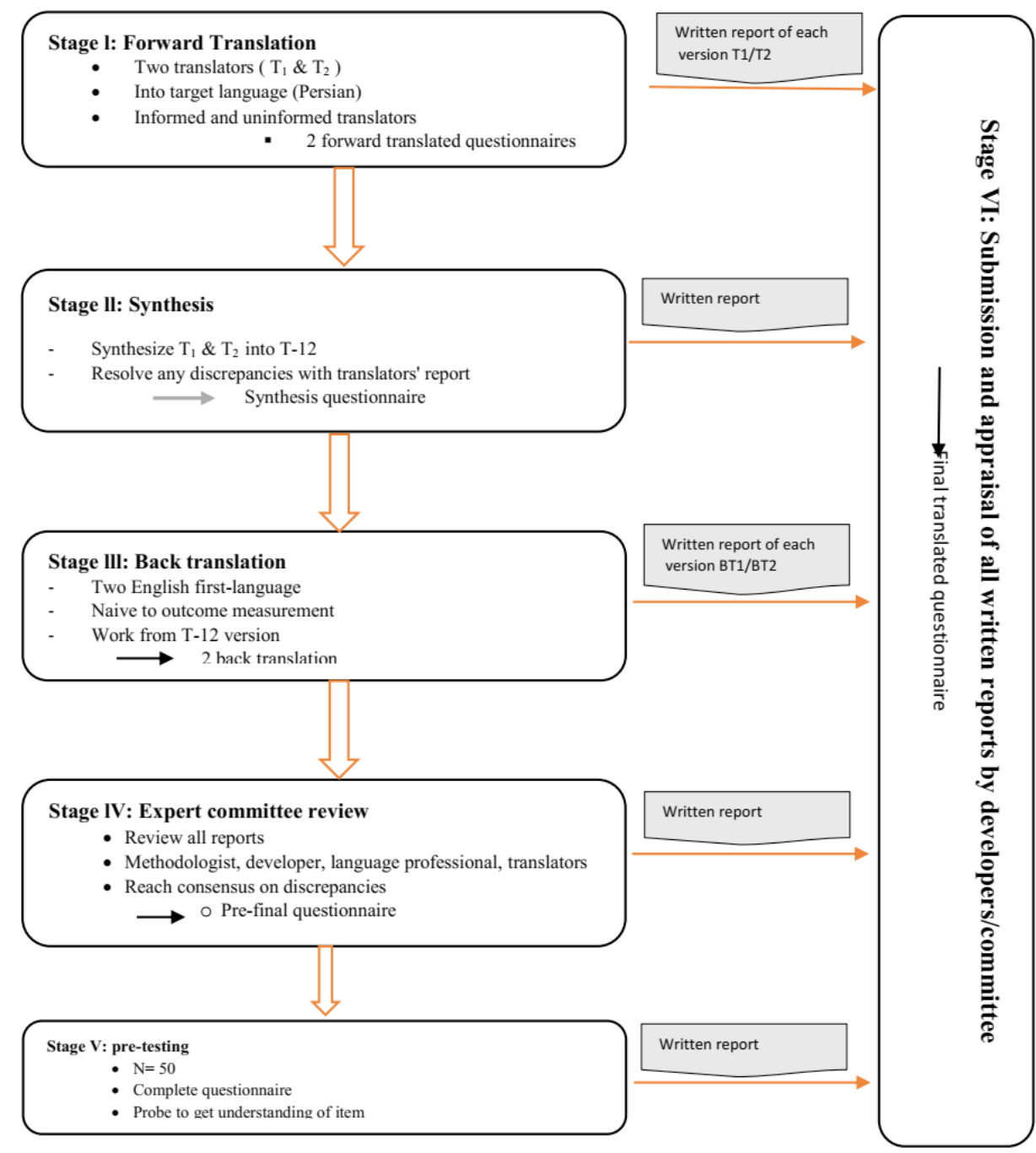

Figure 1. The cross-cultural adaptation process: from Abma et al. [18] and sourced from Beaton et al. [15]. 
with the questionnaire concept and the other was not. These two versions were analyzed by an expert committee consisting of a psychologist, neuroscientist, ergonomist, psychometrician, translators, and authors. After discussing any discrepancies, a consensus was adopted (synthesis of the translations) [17].

Afterward, a backward translation was made from Persian to English by two additional independent and blinded translators (back translation). The same expert committee, but with all translators, evaluated the semantic, idiomatic, experiential, and conceptual equivalences according to the guidelines (expert committee review). Consensus on the pre-final version was reached and the SAS-Pr was produced.

The pre-final version (pre-testing) was pilot-tested in a population of college students $(\mathrm{N}=50)$. The inclusion criteria included signing written consent to participate and being a smartphone user. The exclusion criteria included the lack of consent, non-use of a smartphone, age $<18$ years, and poor Persian language comprehension. After completing the pre-final SAS-Pr, a short interview with each participant was conducted to test the alternative wording and the face and content validity through readability, understandability, interpretation, and cultural relevance was checked. Further feedback and consensus from the expert panel enabled acceptance of the final version of the SAS-Pr.

Psychometric evaluation of the pre-final version

\section{Reliability and internal consistency}

The test-retest reliability was evaluated, using the intraclass correlation coefficient $\left(\mathrm{ICC}_{2,1}\right)$. One hundred subjects were randomly selected from recruited medical students and the data were recorded at baseline and on repetition between 7 and 14 days [16].

The internal consistency was evaluated, using Cronbach's alpha. The value between 0.7 and 0.95 was considered evidence of acceptable reliability [19].

\section{Validity}

The face validity of the Persian SASQ was established through the opinions of the experts throughout the crosscultural adaptation phase. It was also achieved through a qualitative analysis of the suggested comments provided by the participants in the pretest validity phase.

\section{Results}

\section{Samples characteristics}

A total of 100 students (mean age $=24.46$ years, $42 \%$ male) from 3 different medical university campuses in Tehran, Iran, were recruited to participate in the testretest analysis. Table 1 presents the socio-demographic and descriptions of smartphone use patterns.

\section{Cross-cultural adaptation process}

There was minimal difficulty during the implementation of forwarding and back translation, which corresponded to the original version. Minor revisions were applied to the text based on cultural relevance. Most students had difficulty accepting item 15 . Consequently, it was revised and translated as: "I am restless and worried when I don't have my cellphone in hand" in the Persian language. In items 24 and 25, the "telegram" was added because of its

Table 1. Socio-demographic and descriptions of mobile smartphone use pattern

\begin{tabular}{|c|c|c|c|}
\hline \multicolumn{2}{|c|}{ Variables } & \multirow{2}{*}{$\begin{array}{l}\text { No. } \\
100\end{array}$} & \multirow{2}{*}{$\begin{array}{c}\text { Age (Mean } \pm S D) \\
24.46 \pm 4.14\end{array}$} \\
\hline & & & \\
\hline \multirow{2}{*}{ Gender } & Male & 42 & $25.02 \pm 4.3$ \\
\hline & Female & 58 & $24.05 \pm 3.9$ \\
\hline \multirow{2}{*}{ Marriage status } & Single & 68 & - \\
\hline & Married & 32 & - \\
\hline \multirow{6}{*}{ Purpose of smartphone use } & Social networks & 34 & - \\
\hline & SMS & 25 & - \\
\hline & Email & 10 & - \\
\hline & Internet & 11 & - \\
\hline & Read news and books & 14 & - \\
\hline & Other & 6 & - \\
\hline
\end{tabular}


Table 2. Item analysis and internal consistency of the Persian SAS

\begin{tabular}{|c|c|c|c|c|c|c|c|c|c|}
\hline Items & 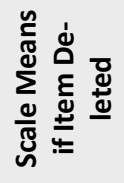 & 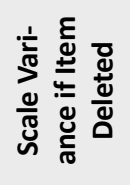 & 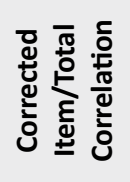 & 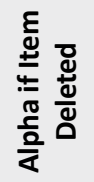 & $\underset{ \pm}{\underline{E}}$ & 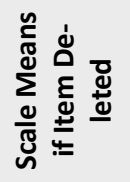 & 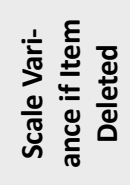 & 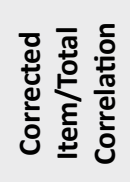 & 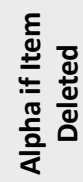 \\
\hline 1 & 102.57 & 802.100 & 0.658 & 0.946 & 18 & 102.64 & 798.481 & 0.569 & 0.947 \\
\hline 2 & 102.85 & 796.821 & 0.717 & 0.946 & 19 & 103.66 & 819.574 & 0.390 & 0.948 \\
\hline 3 & 102.73 & 798.949 & 0.689 & 0.946 & 20 & 102.82 & 805.934 & 0.571 & 0.947 \\
\hline 4 & 102.51 & 808.710 & 0.579 & 0.947 & 21 & 102.91 & 802.977 & 0.562 & 0.947 \\
\hline 5 & 102.80 & 803.546 & 0.661 & 0.946 & 22 & 103.74 & 811.190 & 0.507 & 0.947 \\
\hline 6 & 103.07 & 811.247 & 0.545 & 0.947 & 23 & 103.16 & 809.281 & 0.548 & 0.947 \\
\hline 7 & 103.05 & 809.672 & 0.569 & 0.947 & 24 & 102.60 & 804.680 & 0.595 & 0.947 \\
\hline 8 & 102.68 & 809.330 & 0.584 & 0.947 & 25 & 102.03 & 802.054 & 0.569 & 0.947 \\
\hline 9 & 103.30 & 812.788 & 0.525 & 0.947 & 26 & 102.77 & 801.370 & 0.602 & 0.946 \\
\hline 10 & 103.78 & 813.552 & 0.514 & 0.947 & 27 & 101.77 & 806.576 & 0.561 & 0.947 \\
\hline 11 & 103.83 & 811.205 & 0.560 & 0.947 & 28 & 101.95 & 804.405 & 0.579 & 0.947 \\
\hline 12 & 103.86 & 813.055 & 0.516 & 0.947 & 29 & 102.36 & 803.497 & 0.622 & 0.946 \\
\hline 13 & 103.88 & 811.530 & 0.534 & 0.947 & 30 & 102.71 & 797.741 & 0.685 & 0.946 \\
\hline 14 & 103.63 & 809.181 & 0.540 & 0.947 & 31 & 102.90 & 801.6330 & 0.657 & 0.946 \\
\hline 15 & 102.78 & 799.457 & 0.666 & 0.946 & 32 & 102.77 & 804.367 & 0.577 & 0.947 \\
\hline 16 & 102.84 & 804.099 & 0.588 & 0.947 & 33 & 103.44 & 801.743 & 0.650 & 0.946 \\
\hline 17 & 103.76 & 809.799 & 0.545 & 0.947 & & & & & \\
\hline
\end{tabular}

Overall Cronbach's a=0.948; Mean $\pm S D=106.19 \pm 29.25$.

Iranian Rehabilitation Journa

high usage among Iranian and Persian culture. The prefinal questionnaire was administered to 50 students $(62 \%$ females, age $=21.0 \pm 2.1$ years). All subjects reported no problems or difficulties in completing the SAS-Pr.

\section{Reliability analysis}

Test-retest reliability, with follow-up assessment at 2 weeks, was high $\left(\mathrm{ICC}_{2,1}=0.81,95 \% \mathrm{CI}=0.72-0.87\right)$ and confirmed temporal stability. Internal consistency, measured with Cronbach's alpha, was 0.948 for the 33 items in the SAS-Pr. The corrected item to total correlation coefficient was between 0.39 and 0.71 , which indicated a statistically significant positive correlation $(\mathrm{P}<0.01)$. Furthermore, the obtained alpha for each item through an item-deleted method was calculated (Table 2).

\section{Validity}

Face validity obtained by the expert committee for the SAS-Pr was high. They also considered the SAS-Pr useful in assessing addiction to smartphone use. The subjects of pretest assessment $(\mathrm{N}=50)$ found the scale to be complete in terms of their requirements and it was conclusive.

\section{Discussion}

The current study aimed at assessing the cross-cultural adaptation of the SAS to Persian to produce the SAS-Pr and to assess the reliability and validity of the final tool. We used the SAS for translation and cultural adaptation because it is a multiple-choice short length scale that is easy to understand, rate, and apply. The process of crosscultural adaptation was performed based on previously published guidelines [15]. Finally, a Persian version was 
obtained, which was culturally and linguistically equivalent to the original version.

Some changes in literal language translation were performed to increase the comprehensibility and readability of the questionnaire within the Persian cultural context. All of the changes were confirmed by the current authors of the research and the original author. Acceptance of item 15 was also difficult in the Malay version that was translated to "Feeling impatient and restless when I do not have a smartphone" [14]. Similarly, in the Persian version, it was translated to "I am restless and worried when I don't have my smartphone in hand". Also, in the present study, we added the word 'Telegram' in items 24 and 25 because of the ongoing prevalent use of Telegram applications in Iranian culture. In two other versions, the Spanish and Turkish versions $[2,20]$, there were no reported changes nor cultural adaptations.

In the current study, two types of consistency were assessed; over time reliability and internal consistency across items. The test-retest reliability coefficient was $\mathrm{r}=0.81$ identical to that of the Turkish $(\mathrm{r}=0.81)$ [2] and very close to Malay version $(\mathrm{r}=0.85)$ [14]. In the original [8] and Arabic [21] versions of the SAS, test-retest reliability results were not reported.

The Cronbach's alpha coefficient for the total scale was 0.948 . It indicated that the internal consistency was only below the upper-limit threshold [22] that was a similar finding to the Turkish, Malay, and the original version (0.947, 0.94, and 0.967, respectively) [2, 8, 14]. However, it should be noted that if the alpha value exceeds 0.95 , as found in the original version $[2,8,14]$, then, item redundancy is present and too many questions have similarly asked the same construct. This, in addition to the Persian and Malay versions approaching the upper limit of $\alpha=0.95$ thresholds, suggests that the shortening of the question and reduction of the total 33 items could be considered something beyond the scope of this study. Also, the short version of the SAS showed a Cronbach's alpha coefficient of $0.91,0.85,0.79,0.88$, and 0.90 [20] for the original, German, Italian, Spanish, and Belgian versions, respectively [23-25]. This result demonstrates that the SAS-Pr has a very high but suitable level of internal consistency. We also computed the item to the total correlation coefficient (0.39-0.71), which was again close to that of the Turkish version (0.39-0.77) [2].

\section{Limitations and strengths}

The first limitation is the lack of generalizability of the sample. The present study was conducted on a sample of medical students and, consequently, cannot be generalized to the total adult Persian population. However, this age and occupation group is recognized as high users of smartphone. Further research is required with different samples to broaden the population psychometrics of the SAS-Pr. This is the first study on the SAS in a Persian population and the research in this field is limited.

The strengths of the study include its rigor and thoroughness in following the cultural and linguistic adaptation and translation guidelines. This is enhanced by the continuity in the findings of the translators and researchers involved when reaching a consensus version. Furthermore, the final version was specific to a Persian-speaking population as the sample demographic was that of a higher smartphone user group. Lastly, the consistency with other cultural adaptations supports its consideration for adoption as is the necessity to consider the potential for item redundancy.

\section{Conclusions}

This study has described the cultural adaptation and reliability of the SAS-Pr, an instrument designed to assess the addiction to smartphone usage. The SAS-Pr was translated and culturally adapted in an Iranian population for Persian speakers and, then, tested on a reliability sample. The SAS-Pr had high test-retest reliability and internal consistency. The latter may require further consideration with the possibility of shortening the questionnaire to minimize the risk of item redundancy and subsequent user burden.

\section{Ethical Considerations}

\section{Compliance with ethical guidelines}

This study was approved by the Ethics Committee of University of Social Welfare and Rehabilitation Sciences (Code: IR.USWR.REC.1398016). Informed consent was obtained from all participants included in the study.

\section{Funding}

This article has been extracted from the MSc thesis of the first author in the Department of Ergonomics, University of Social Welfare and Rehabilitation Sciences.

\section{Authors' contributions}

Designing the study: Hamidreza Mokhrarinia and Mohammadreza Khodaie Ardakani; Manuscript preparation: Charls Philip Gabel; Literature \& research stud- 
ies: Mahta Rafinia; Statistical analysis: Gholamreza Ghaedamini Harouni; Original draft of the manuscript: Hamidreza Mokhtarinia and Charls Philip Gabel; All authors contributed to and approved the final manuscript.

\section{Conflict of interest}

All authors declared no conflict of interest.

\section{References}

[1] ChaSS,SeoBK.Smartphoneuseand smartphoneaddictionin middle school students in Korea: Prevalence, social networking service, and game use. Health Psychology Open. 2018 5(1): 2055102918755046. [DOI:10.1177/2055102918755046] [PMID] [PMCID]

[2] Demirci K, Orhan H, Demirdas A, Akpinar A, Sert H. Validity and reliability of the Turkish version of the Smartphone Addiction Scale in a younger population. Klinik Psikofarmakoloji Bülteni-Bulletin of Clinical Psychopharmacology. 2014; 24(3):226-34. [DOI:10.5455/bcp.20140710040824]

[3] Ju YW, Lee KN, Choi YJ, Youn EJ. 2017 survey on the Internet usage. Naju: Korea Internet \& Security Agency; 2018 https:/ / k-erc.eu/wp-content/uploads/2018/07/2017-Survey-on-the-Internet-Usage.pdf

[4] Committee on a National Agenda for the Prevention of Disabilities, Institute of Medicine. Disability in America: Towards a national agenda for prevention. Pope A, Tarlow A, editors. Washington, D.C.: National Academy Press; 1991. https:// books.google.com/books?id=aZZ4y_-e3kMC\&dq

[5] Kermani H. Smartphone practice and lifestyle: The case of urban Iran. Journal of Media Studies. 2017; 32(1):33-59. http://journals.pu.edu.pk/journals/index.php/jms/article/view/1935/0

[6] Billieux J, Van der Linden M, d'Acremont M, Ceschi G, Zermatten A. Does impulsivity relate to perceived dependence on and actual use of the mobile phone? Applied Cognitive Psychology. 2007; 21(4):527-37. [DOI:10.1002/acp.1289]

[7] Al-Hadidi F, Bsisu I, AlRyalat SA, Al-Zu'bi B, Bsisu R, Hamdan $\mathrm{M}$, et al. Association between mobile phone use and neck pain in university students: A cross-sectional study using numeric rating scale for evaluation of neck pain. PLoS One. 2019; 14(5):e0217231. [DOI:10.1371/journal.pone.0217231] [PMID] [PMCID]

[8] Kwon M, Lee JY, Won WY, Park JW, Min JA, Hahn C, et al Development and validation of a Smartphone Addiction Scale (SAS). PLoS One. 2013; 8(2):e56936. [DOI:10.1371/journal. pone.0056936] [PMID] [PMCID]

[9] Lin YH, Chang LR, Lee YH, Tseng HW, Kuo TBJ, Chen SH. Development and validation of the Smartphone Addiction Inventory (SPAI). PLoS One. 2014; 9(6):e98312. [DOI:10.1371/journal. pone.0098312] [PMID] [PMCID]
[10] Widyanto L, McMurran M. The psychometric properties of the internet addiction test. CyberPsychology \& Behavior. 2004; 7(4):443-50. [DOI:10.1089/cpb.2004.7.443] [PMID]

[11] Martinotti G, Villella C, Di Thiene D, Di Nicola M, Bria P, Conte G, et al. Problematic mobile phone use in adolescence: A cross-sectional study. Journal of Public Health. 2011; 19(6):545-51. [DOI:10.1007/s10389-011-0422-6]

[12] Mohammadsalehi N, Mohammadbeigi A, Jadidi R, Anbari Z, Ghaderi E, Akbari M. Psychometric properties of the Persian language version of Yang Internet Addiction Questionnaire: An explanatory factor analysis. International Journal of High Risk Behaviors \& Addiction. 2015; 4(3):e21560. [DOI:10.5812/ijhrba.21560] [PMID] [PMCID]

[13] Mohammadi Kalhori S, Mohammadi MR, Alavi SS, Jannatifard F, Sepahbodi Gh, Baba Reisi M, et al. Validation and psychometric properties of Mobile Phone Problematic Use Scale (MPPUS) in university students of Tehran. Iranian Journal of Psychiatry. 2015; 10(1):25-31. [PMID] [PMCID]

[14] Ching SM, Yee A, Ramachandran V, Lim SMS, Sulaiman WAW, Foo YL, et al. Validation of a Malay version of the Smartphone Addiction Scale among medical students in Malaysia. PloS One. 2015; 10(10):e0139337. [DOI:10.1371/journal. pone.0139337] [PMID] [PMCID]

[15] Beaton DE, Bombardier C, Guillemin F, Ferraz MB Guidelines for the process of cross-cultural adaptation of self-report measures. Spine. 2000; 25(24):3186-91. [DOI:10.1097/00007632-200012150-00014] [PMID]

[16] Mokhtarinia HR, Hosseini A, Maleki-Ghahfarokhi A, Gabel CP, Zohrabi M. Cross-cultural adaptation, validity, and reliability of the Persian version of the spine functional index. Health and Quality of Life Outcomes. 2018; 16:95. [DOI:10.1186/s12955-018-0928-5] [PMID] [PMCID]

[17] Shafeei A, Mokhtarinia HR, Maleki-Ghahfarokhi A, Piri L. Cross-cultural adaptation, validity, and reliability of the Persian version of the Orebro Musculoskeletal Pain Screening Questionnaire. Asian Spine Journal. 2017; 11(4):520-30 [DOI:10.4184/asj.2017.11.4.520] [PMID] [PMCID]

[18] Abma FI, Amick III BC, Brouwer S, van der Klink JJL, Bültmann U. The cross-cultural adaptation of the Work Role Functioning Questionnaire to Dutch. Work. 2012; 43(2):20310. [DOI:10.3233/WOR-2012-1362] [PMID]

[19] Nunnally JC. Psychometric theory. New York: McGraw-Hill; 1978. https://books.google.com/books?id= WE59AAAAMAAJ\&dq

[20] Lopez-Fernandez O. Short version of the Smartphone Addiction Scale adapted to Spanish and French: Towards a cross-cultural research in problematic mobile phone use Addictive Behaviors. 2017; 64:275-80. [DOI:10.1016/j.addbeh.2015.11.013] [PMID]

[21] Sfendla A, Laita M, Nejjar B, Souirti Z, Touhami AAO, Senhaji M. Reliability of the Arabic Smartphone Addiction Scale and smartphone addiction scale-short version in two different Moroccan samples. Cyberpsychology, Behavior, and Social Networking. 2018; 21(5):325-32. [DOI:10.1089/cyber.2017.0411] [PMID]

[22] Streiner DL, Norman GR, Cairney J. Health measurement scales: A practical guide to their development and use. New York, NY: Oxford University Press; 2015. [DOI:10.1093/ med/9780199685219.001.0001] 
[23] Kwon M, Kim DJ, Cho H, Yang S. The smartphone addiction scale: development and validation of a short version for adolescents. PLoS One. 2013; 8(12):e83558. [DOI:10.1371/ journal.pone.0083558] [PMID] [PMCID]

[24] Haug S, Castro RP, Kwon M, Filler A, Kowatsch T, Schaub MP. Smartphone use and smartphone addiction among young people in Switzerland. Journal of Behavioral Addictions. 2015; 4(4):299-307. [DOI:10.1556/2006.4.2015.037] [PMID] [PMCID]

[25] De Pasquale C, Sciacca F, Hichy Z. Italian validation of Smartphone Addiction Scale Short Version for adolescents and young adults (SAS-SV). Psychology. 2017; 8(10):1513-8. [DOI:10.4236/psych.2017.810100] 